\title{
Implantação de consórcios públicos intermunicipais de resíduos sólidos urbanos: Monte do Carmo e Silvanópolis, Tocantins
}

O presente trabalho teve como objetivo analisar a viabilidade técnica para implantação de um consórcio intermunicipal de resíduos sólidos entre Monte do Carmo/TO e Silvanópolis/TO visando a destinação final e adequada dos resíduos tendo como embasamento a Política Nacional de Resíduos Sólidos instituído pela Lei no 12.305/2010. Para tal, foi realizado visita aos municípios com aplicação de questionário aos responsáveis pela Secretaria de Meio Ambiente a fim de obter conhecimento sobre a situação atual dos mesmos acerca da coleta e destinação dos resíduos. Também foi realizado análise de dados georreferenciados gerados através do programa ArchGis para determinação de áreas ótimas para a instalação de um aterro sanitário, baseados em critérios estabelecidos pela Resolução CONAMA 404/2008: declividade, recursos hídricos, solos, distância de rodovias, do perímetro urbano e de Áreas de Preservação Permanente. Concluiu-se que ambos municípios se encontram em desconformidade com a Política Nacional de Resíduos Sólidos, uma vez que ainda descartam seus resíduos em lixões à céu aberto sem qualquer tipo de controle ambiental, embora em Silvanópolis já esteja sendo desenvolvido programas de reciclagem de alguns materiais. Em análise de dados georreferenciados é possível garantir a viabilidade técnica para construção de tal aterro consorciado em região próxima à rodovia que liga os dois municípios.

\section{Implementation of intermunicipal public consortium of urban solid waste: Monte do Carmo and Silvanópolis, Tocantins}

\begin{abstract}
The present work aimed to analyze the technical feasibility for the implementation of an intermunicipal waste consortium between Monte do Carmo/TO and Silvanópolis/TO use the final destination and the appropriate waste based on the National Solid Waste Policy established by Law no. 12.305/2010. To this end, a visit was made to the municipalities with a questionnaire applied to the employees of the Secretariat of the Environment, to obtain knowledge about their current situation regarding waste collection and disposal. The analysis of georeferenced data generated through the ArchGis program was also performed to determine optimal areas for the installation of a toilet, used in tests applied by Resolution CONAMA 404/2008: Slope, Water Resources, Soils, Distance Roads, Urban Perimete and Areas of Permanent Preservation. It was finished that both municipalities are in non-compliance with the National Solid Waste Policy, since their waste is stil disposed of in open dumps without any environmental control, although recycling programs are already being implemented in Silvanópolis of some materials. In georeferenced data analysis, it is possible to guarantee the technical viability for the construction of a consortium landfill in the region near the highway that connects the two counties.
\end{abstract}

Keywords: Urban Solid Wast; Consortium; Landfill.

Topic: Engenharia Civil

Reviewed anonymously in the process of blind peer.
Received: 11/12/2019

Approved: 20/02/2019

Jacqueline Pereira Cursino Alves (iD

Instituto Tocantinense Presidente Antônio Carlos, Brasil

http://lattes.cnpq.br/6126098089554230

http://orcid.org/0000-0002-7903-1218

jacqcursino@gmail.com

Ana Paula Lustosa Ribeiro (in

Instituto Tocantinense Presidente Antônio Carlos, Brasil

http://lattes.cnpq.br/8012091741821703

http://orcid.org/0000-0002-8067-0375

anapaula.ribeiro@prosul.com

Referencing this:

ALVES, J. P. C.; RIBEIRO, A. P. L.. Implantação de consórcios públicos intermunicipais de resíduos sólidos urbanos: Monte do Carmo e Silvanópolis, Tocantins. Engineering Sciences, v.8, n.1, p.8-16, 2020. DOI: http://doi.org/10.6008/CBPC2318-3055.2020.001.0002 


\section{INTRODUÇÃO}

O impasse da limpeza urbana não está relacionado apenas à remoção dos resíduos das vias públicas e edificações, pois o ponto mais crítico localiza-se na destinação final adequada aos resíduos coletados (MONTEIRO et al., 2001), o que leva a classificar o correto gerenciamento dos resíduos sólidos como um dos principais desafios no início do novo milênio, dos grandes centros urbanos (REICHERT, 2013).

A quantidade de lixo gerado mundialmente é superabundante, considerando-se o fato do estilo de vida da sociedade, composta por mais de 7 bilhões de habitantes, basear-se no consumismo (BLOOM, 2011). Teixeira et al. (2013) evidencia que a alta produção de lixo tem correlação direta com a demografia e concentração de renda pela produção dos bens de consumo. Contudo esse problema ultrapassa a questão econômica tornando-se uma realidade de países pobres também.

Todavia, a maior produção de lixo é verificada em países ricos, industrializados e em desenvolvimento, como no Brasil (ABRELPE, 2010). O descarte inadequado de RSU acarreta em uma série de problemas, seja socioambiental, como degradação do solo, acentuação de enchentes, e poluição do ar, ou de saúde pública, tanto para pessoas que costumam operar em lixões quanto para a população do entorno, ocasionadas pela proliferação de vetores (OLIVEIRA et al., 2016).

Diversas ações e projetos vêm sendo apresentados nos últimos 10 anos, visando a melhoria da problemática relacionada à disposição final inadequada e tratamentos dos RSU. Em 2016, 78,6\% dos municípios brasileiros possuíam serviços de manejo de resíduos sólidos, apresentando um aumento de 3\% se comparado ao ano anterior. E ainda, pouco mais de $69,6 \%$ dos municípios apontaram alguma iniciativa de coleta seletiva, o que demonstra o interesse dos mesmos em mudar o cenário catastrófico atual (ABRELPE, 2017).

Em se tratando de termos legislativos, atualmente encontra-se em vigor a Lei Federal $n^{\circ}$ 12.305/2010, que tenciona à gestão integrada e gerenciamento adequado dos resíduos sólidos através da determinação das responsabilidades dos geradores, direitos e deveres e da necessidade de quantificação e caracterização dos resíduos, além de instituir a Política Nacional dos Resíduos Sólidos (PNRS) (BRASIL, 2010). A PNRS tem como disposição geral promover a saúde pública e a qualidade ambiental. Para tal, a utilização de lixões torna-se estritamente proibida, exigindo dos municípios a adoção de medidas apropriadas para disposição e tratamento dos resíduos, como a implantação de aterros sanitários (RIBEIRO, 2011).

Durante um longo período de tempo, os municípios brasileiros fizeram do lixão o método mais utilizado para descarte de rejeitos sólidos. Esse método baseia-se na disposição dos mesmos em um local pré-determinado, à céu aberto, e sem nenhum tipo de cuidado com o solo e o ambiente, tornando-se comum a presença de animais atraídos pelo mau cheiro dos materiais orgânicos e de coletores de material reciclável, que ficam expostos a perigos de corte, perfurações, animais peçonhentos e contaminações (MONTEIRO et al., 2001).

O aterro sanitário, por ter sua implantação regulamentada por normas técnicas, possuir drenagem das águas pluviais, tratamento dos gases originados da decomposição, captação e tratamento do chorume, 
controle do solo e das águas subterrâneas, é classificado como a forma de descarte mais adequada para os RSU (ELK, 2007).

A Lei Federal $n^{\circ} 12.305 / 2010$ estabeleceu que todos os estados e municípios deveriam acabar com a utilização dos lixões, que por sua vez devem ser substituídos por aterros sanitários, além de estabelecimento de coleta seletiva, aplicação de reciclagem, compostagem e tratamento do lixo, no prazo de até 4 anos, ou seja até 2014.

Segundo matéria eletrônica divulgada no mês de setembro de 2018 (Jornal do Tocantins, 2018), o estado do Tocantins faz uso de 129 lixões, sete aterros controlados (Brejinho de Nazaré, Santa Rosa, Colinas do Tocantins, Itacajá, Itupiratins, Lavandeira e Dois Irmãos) e apenas 3 aterros sanitários (Araguaína, Gurupi e Palmas). Em 2019 mais um aterro entrou em funcionamento, no município de Porto Nacional.

Em virtude de limitações financeiras e técnicas muitos municípios encontram-se com dificuldades para regularizar a gestão de resíduos, dado que o custo para implantação e operacionalização dessa atividade é bastante elevado (FELICORI, 2015). Brasil (2010) sugere, por meio da PNRS, à adoção de consórcios intermunicipais, objetivando a solução da problemática, uma vez que com o estabelecimento do mesmo as despesas são divididas entre as administrações públicas e facilitaria a implantação do serviço.

Tendo em vista o exposto o presente estudo teve como objetivo analisar a viabilidade técnica para implantação de um consórcio intermunicipal de resíduos sólidos entre Monte do Carmo -TO e Silvanópolis TO visando a destinação final e adequada dos resíduos sólidos tendo como embasamento a Política Nacional de Resíduos Sólidos instituído pela Lei no 12.305/2010.

\section{METODOLOGIA}

A pesquisa em questão foi de caráter quali-quantitativo, através de consulta em material bibliográfico e legislação vigente que contemplam o tema abordado. Para melhor conhecimento a respeito dos municípios, sua atual situação quanto aos resíduos sólidos e possíveis condições que possam interferir positivamente ou não na formação de um consórcio foi realizado uma visita técnica aos mesmos, no qual foi aplicado um questionário aos Secretários de Meio Ambiente.

Para análise da viabilidade técnica do consórcio foi observado algumas diretrizes de planejamento conforme utilizado por Suzuki et al. (2009), que tem como suporte critérios demográficos, logísticos (distância entre sedes urbanas e malha viária existente com distância máxima de 50 km entre as sedes urbanas dos municípios e o local onde se localizaria o aterro intermunicipal e com boas condições de trafegabilidade) e gestão por unidades hidrográficas (evitar a transferência de resíduos entre as bacias hidrográficas).

Para análise da malha viária (condições de trafegabilidade, tipo de asfaltamento e distância viária) e localização das unidades hidrográficas estaduais foi realizado consulta a um conjunto mapas atualizados gerados pelo DNIT e Embrapa Monitoramento por Satélite em parceria com a Diretoria de Zoneamento Ecológico-Econômico (DZE), da Secretaria de Planejamento (SEPLAN) do Estado do Tocantins, além de confecção de mapas georreferenciados com auxílio do programa ArchGIS. 
As áreas ótimas para a instalação de um aterro sanitário foram identificadas com base nos seis critérios geotécnicos de exclusão de área, conforme Resolução CONAMA no 404 (BRASIL, 2008): declividade, recursos hídricos, solos, distância de rodovias, do perímetro urbano e de Áreas de Preservação Permanente, através da elaboração e consulta de mapas específicos para cada um dos critérios.

\section{RESULTADOS E DISCUSSÃO}

\section{Situação atual dos municípios}

O município de Monte do Carmo localiza-se na região Central do Estado do Tocantins, Mesorregião Oriental. Situa-se nas coordenadas $-10 \circ 45^{\prime} 48^{\prime \prime}$ de latitude Sul e 4806' 32 " de longitude Oeste. Limita-se ao norte com os municípios de Palmas, Santa Tereza do Tocantins e Palmas; ao sul com o município de Silvanópolis; a leste com o município de Ponte Alta do Tocantins e a oeste como o município de Porto Nacional. Possui área territorial total de $3.616,674 \mathrm{~km}^{2}$ e população atual estimada de 7.947 pessoas (IBGE, 2010).

Atualmente o gerenciamento dos Resíduos Sólidos (domiciliar, hospitalar, de construção civil, galhas e podas) é realizado pela prefeitura municipal em $100 \%$ do perímetro urbano, o qual é destinado a um lixão à céu aberto concentrado próximo à sede administrativa do município em local de fácil acesso, com área total de $48.400 \mathrm{~m}^{2}$. Os resíduos sólidos domésticos são depositados em camadas dentro de valas sem qualquer tipo de impermeabilização do solo (Figura 1).

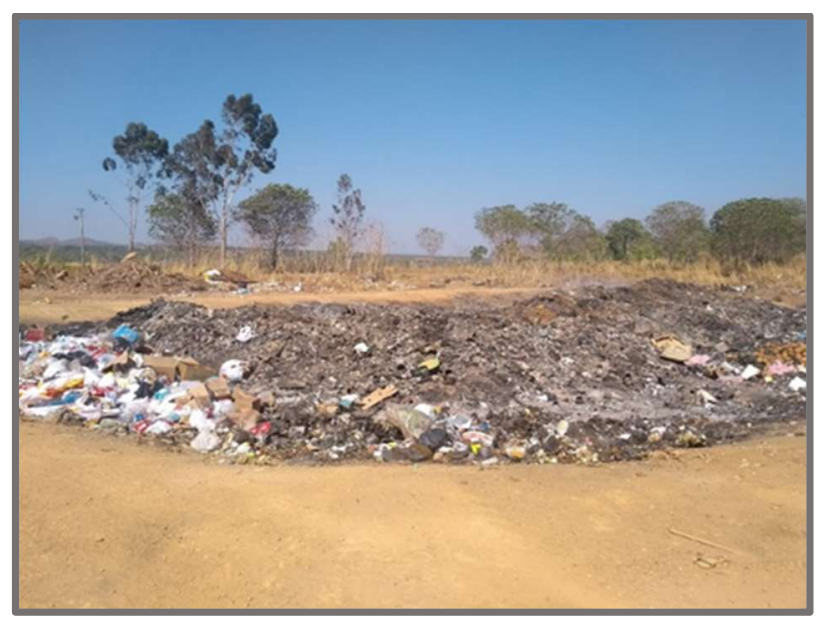

Figura 1: Lixão à céu aberto em Monte do Carmo/TO.

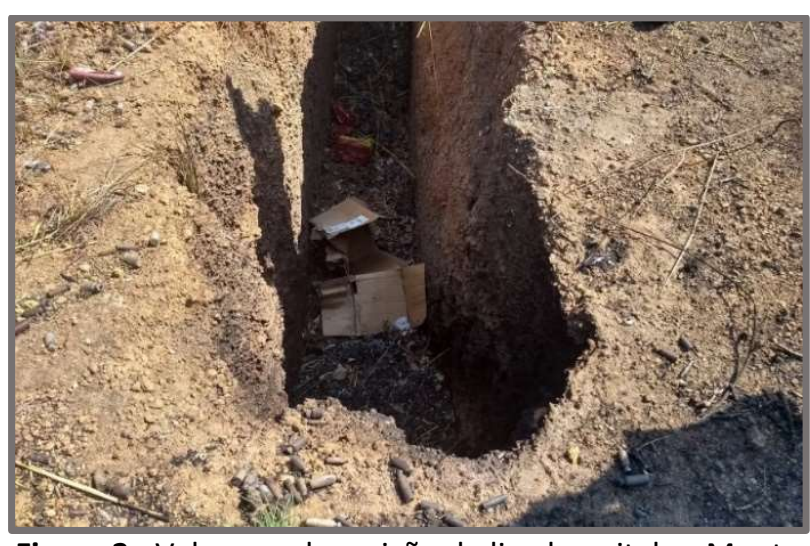

Figura 2: Vala para deposição de lixo hospitalar, Monte do Carmo/TO.

Quanto aos resíduos de construção civil, galhas e podas, são dispostos sob o solo, em local reservado para tal, dentro da área do lixão. Os resíduos hospitalares são dispostos em valas mais profundas onde são posteriormente incinerados, mas também sem impermeabilização do solo (Figura 2), e são recolhidos uma vez por semana ou conforme a necessidade.

O caminhão utilizado na coleta não é próprio para a atividade, sendo alugado e também utilizado para outras atividades como transporte de telhas para área rural (Figura 3). A coleta dos resíduos domésticos, na sede do município é realizada diariamente de segunda à sexta e sábado pela manhã, alternando entre os 6 setores, totalizando $2.000 \mathrm{~kg}$ diários. Um caminhão, com capacidade de transporte de $1.000 \mathrm{~kg}$, é carregado 
por turno (matutino e vespertino), de modo a realizar duas viagens por dia até o lixão.

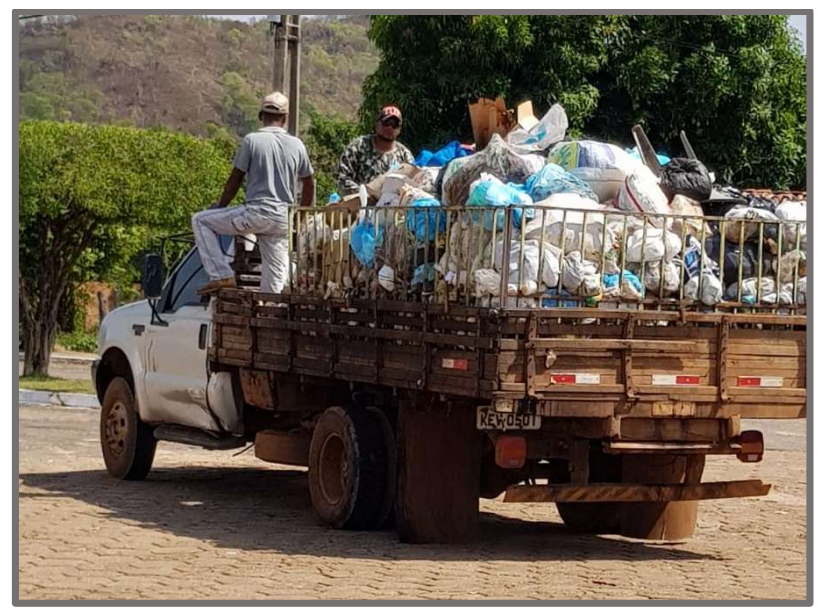

Figura 3: Caminhão de coleta de resíduos sólidos, Monte do Carmo/TO.

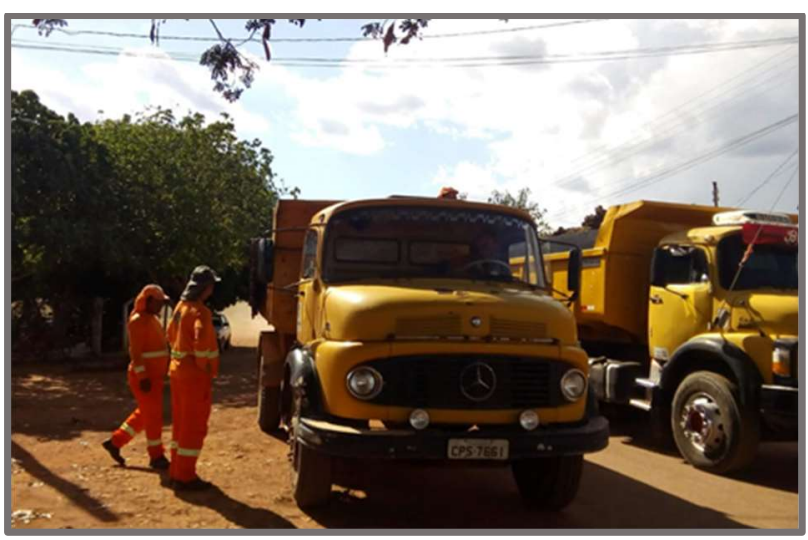

Figura 4: Caminhão de coleta de resíduos sólidos, Silvanópolis/TO.

Não há programa de reciclagem ou separação do RSD no município. O município de Silvanópolis com cerca de 5403 habitantes atuais (IBGE, 2010) está localizado na Mesorregião Oriental do estado, nas coordenadas -11이' 48 ", latitude Sul e 4810'09" longitude Oeste. Com uma área de 2.258,831 km² têm como limites intermunicipais, Monte do Carmo, Ponte Alta do Tocantins, Porto Nacional, Pindorama, Santa Rosa e Ipueiras.

O gerenciamento dos resíduos sólidos no município inicia-se na coleta com auxílio de 2 caminhões alugados (Figura 4), que por sua vez abrange todo o perímetro urbano realizando recolhimento dos resíduos de construção civil, domiciliar, galhos e podas. Os resíduos domiciliares são coletados de segunda a sexta, sendo que nos dois maiores setores são recolhidos todos os dias e nos demais, alternadamente.

Não há serviço de coleta nos assentamentos. Os moradores dessas localidades costumam queimar ou enterrar o próprio lixo. A coleta do lixo hospitalar é realizada mensalmente pela empresa BIOTEC, alocada na capital, de modo a realizar a destinação ambientalmente correta e segura. Os demais resíduos são de responsabilidade do próprio município.

A praticabilidade do conceito de reciclagem já está introduzida no município através da coleta e separação de papelões e pneus. Todo papelão recolhido é enviado para uma cooperativa de reciclagem (COOPERAN) em Palmas/TO, e os pneus são recolhidos pela RECICLAMIP, localizada em Goiânia/GO. A destinação final dos resíduos sólidos de responsabilidade do município ocorre em um lixão à céu aberto, dentro de valas sem nenhum tipo de impermeabilização do solo (Figura 5). Inicialmente, a área em que hoje se localiza o lixão foi projetada para construção de um aterro controlado, contudo as obras não foram concluídas.

Os resíduos de construção civil, podas e galhas são depositados sobre o solo em alguns pontos do terreno em montes próprios (Figura 6), mas que devido a ação do vento acabam recebendo sacolas e materiais mais leves. A área total do lixão é de $25.507 \mathrm{~m}^{3}$ e está localizado na área rural, próximo à Rodovia TO-010. Atualmente encontra-se com cerca e guarita comprometida, além de não possuir nenhum tipo de segurança (Figura 7), viabilizando o acesso a qualquer pessoa. Prova disso é que é comum visualizar focos de 
fogo nas valas (Figura 5), onde os catadores procuram facilitar o recolhimento das latinhas.

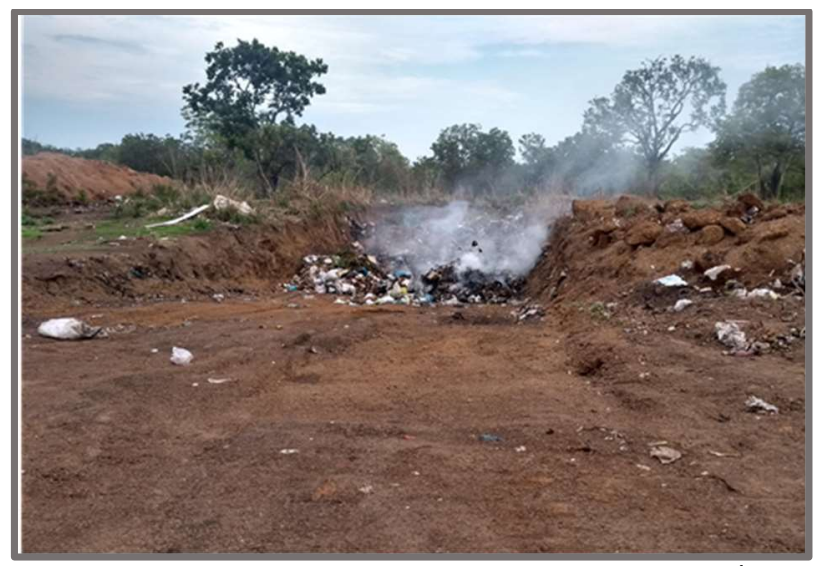

Figura 5: Resíduos sendo queimados, Silvanópolis/TO.

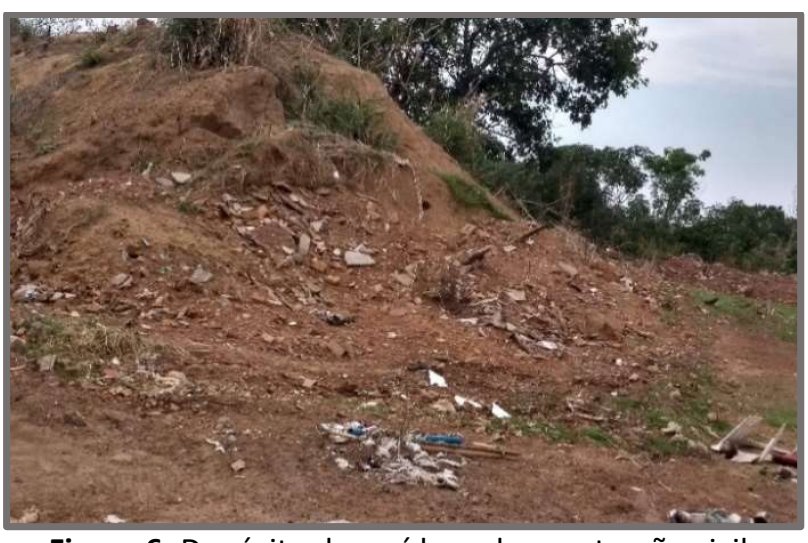

Figura 6: Depósito de resíduos de construção civil, Silvanópolis/TO.

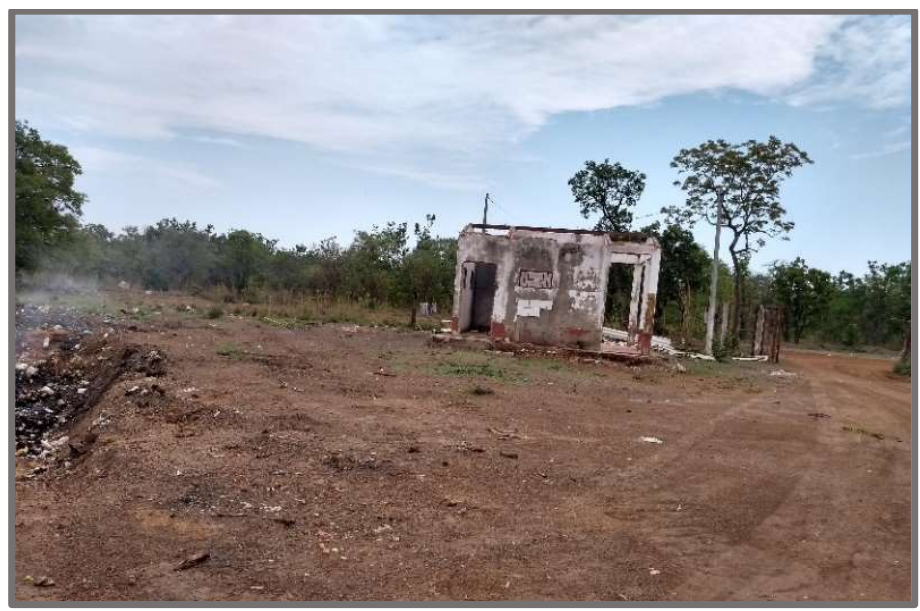

Figura 7: Guarita e acesso do lixão, Silvanópólis/TO.

\section{Análise de georreferenciamento}

A análise de áreas para construção de um aterro sanitário envolve diversos critérios de fundamentação ambiental, social, econômica, técnica e legal, necessitando de uma ferramenta que trabalhe com múltiplas variáveis. Como exemplo, tem-se as técnicas de geoprocessamento que, através de mapas, viabilizam um diagnóstico espacial individualizado e integrados possibilitando a tomada de decisão com base em resultados combinados (RIKILS, 2015).

O sistema de informações geográficas é uma ferramenta estratégica no processo de zoneamento de áreas aptas para instalação de aterros sanitários em conformidade com os critérios definidos pela Resolução CONAMA no 404 de 11 de dezembro de 2008 (RIKILS, 2015), que trata dos critérios e diretrizes para o licenciamento ambiental de aterro sanitário de pequeno porte de resíduos sólidos urbanos, sendo eles critérios restritivos e de aptidão (BORN, 2013).

Os mapas elaborados com base nos critérios determinados pela Resolução CONANA no 404 serão tratados a seguir. Rafael et al. (2007) afirmam que quanto maior a distância do perímetro urbano, maior será a adequabilidade da área para implantação de um aterro, uma vez que a população estará distante de odores, insetos e demais vetores de doenças. Visto que a proposta para um consórcio intermunicipal deve respeitar a distância máxima de $50 \mathrm{~km}$ entre as sedes dos municípios e o local do aterro, o presente estudo analisou a 
viabilidade de áreas que estejam mais próximo ao ponto médio entre as cidades, próximo à TO-365 (limite de Monte do Carmo), de modo a não ficar tão distante para uma delas.

O município de Monte do Carmo distancia-se 54,5 km de Silvanópolis. Pelo mapa da análise de solos (Figura 8) é possível perceber a predominância da classe Latossolo Amarelo e Vermelho-Amarelo na área entre os municípios. Em pesquisa desenvolvida por Benda (2008) os Latossolos foram escolhidos como de maior adequabilidade para a construção de aterros por se tratarem de solos mais estáveis quanto à diminuição de volume, por serem minerais, com elevada permeabilidade, resultando em boas a acentuadas drenagens. $\mathrm{O}$ que fato viabiliza quase toda a área de em análise para construção de aterro.

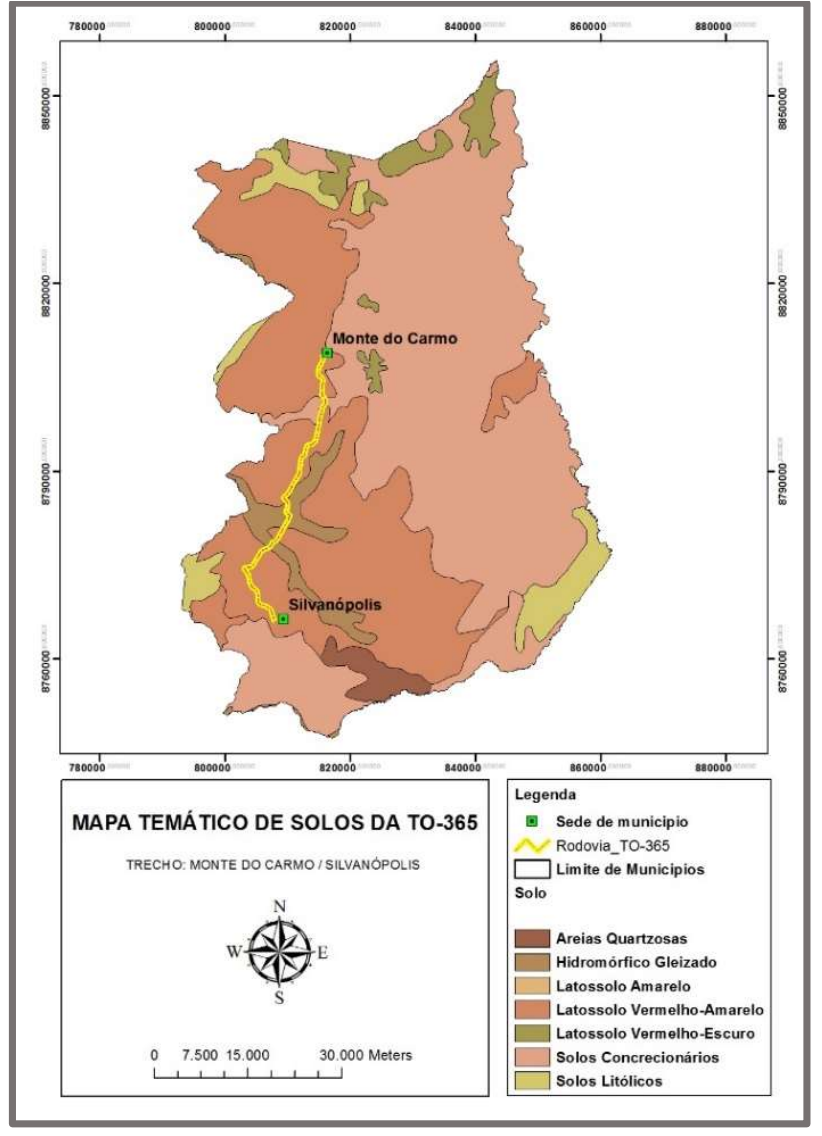

Figura 8: Mapa solos.

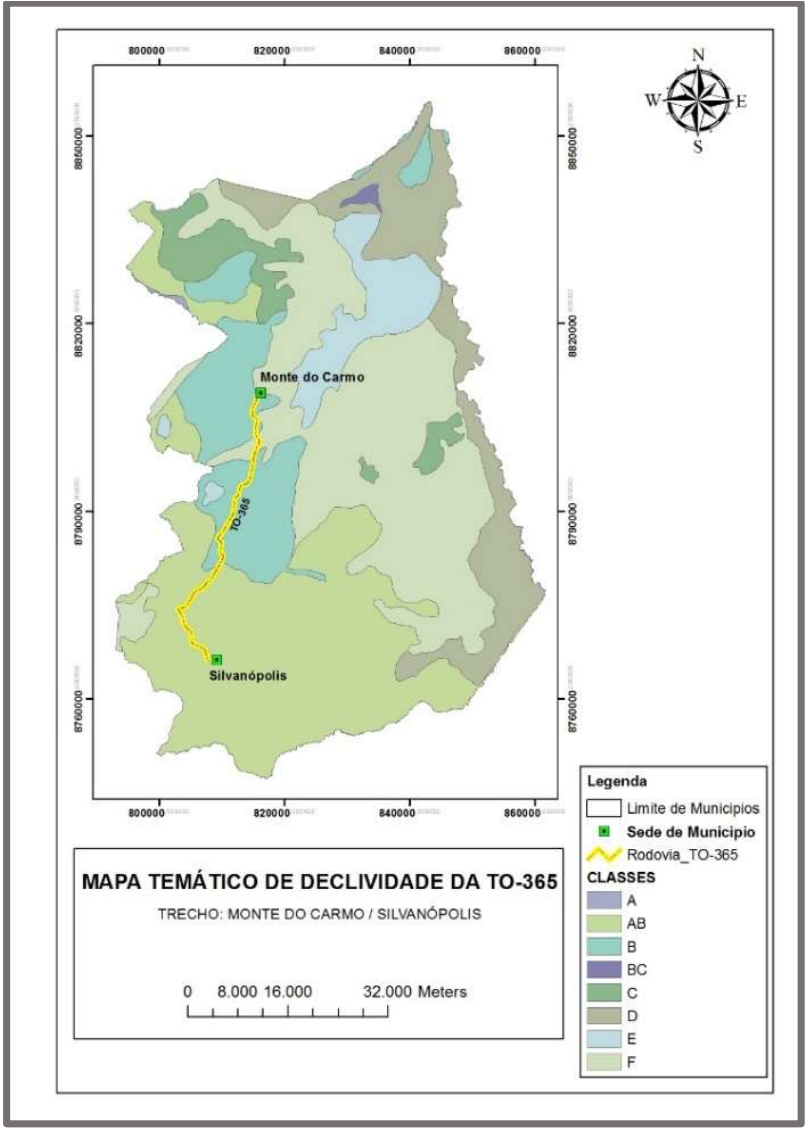

Figura 9: Mapa declividade.

A declividade retrata as alterações de inclinação, podendo ser visualizado através de mapas hipsométricos, que representa a elevação de um terreno através de uma escala de cores. Quanto menor for a declividade, maior a área para implantação do aterro sanitário (RIKILS, 2015). Em observância ao mapa de declividade (Figura 9), observa-se a presença de um baixo relevo, sem grandes declividades, apresentando aumento apenas na região próxima à sede de Monte do Carmo (classe F, declividade acima de 45\%), o que viabiliza as demais áreas para implantação de aterro sanitário com declividade até $10 \%$ (classe $B$ e $A B$ ).

Visando a preservação do solo, Moreira et al. (2008), afirma que áreas com declividade acima de $10 \%$ tornam-se inapropriadas para construção de aterros sanitários, uma vez que tornam o material não consolidado instável, propicia infiltrações e dificulta o escoamento do lixiviado, bem como o transporte até o local.

Visando a preservação dos recursos hídricos, a Portaria no 124 de 20 de agosto de 1980, determina 
que deve ser mantido um distanciamento mínimo de $200 \mathrm{~m}$ para corpos d'água e de $500 \mathrm{~m}$ de rios, além de que o lençol freático deve ter profundidade maior que 4 metros (Figura 10). As distâncias supracitadas objetivam evitar a poluição hídrica por parte dos efluentes oriundos dos aterros que podem ser eventualmente lixiviados.

Como medida de segurança e afim de preservar a malha rodoviária, TO-365, de impactos visuais, sonoros e olfativos, os aterros devem localizar-se em áreas com distâncias de no mínimo $300 \mathrm{~m}$ das rodovias (Figura 10) (GREGÓRIO et al., 2013; RIKILS, 2015). Grande parte das proximidades da TO-365 é ocupada pela agricultura (Figura 8), graças a sua grande potencialidade de uso da terra para fins agrícolas (SEPLAN, 2015), o que acaba inviabilizando tais áreas economicamente, visto que tem grande valor financeiro.

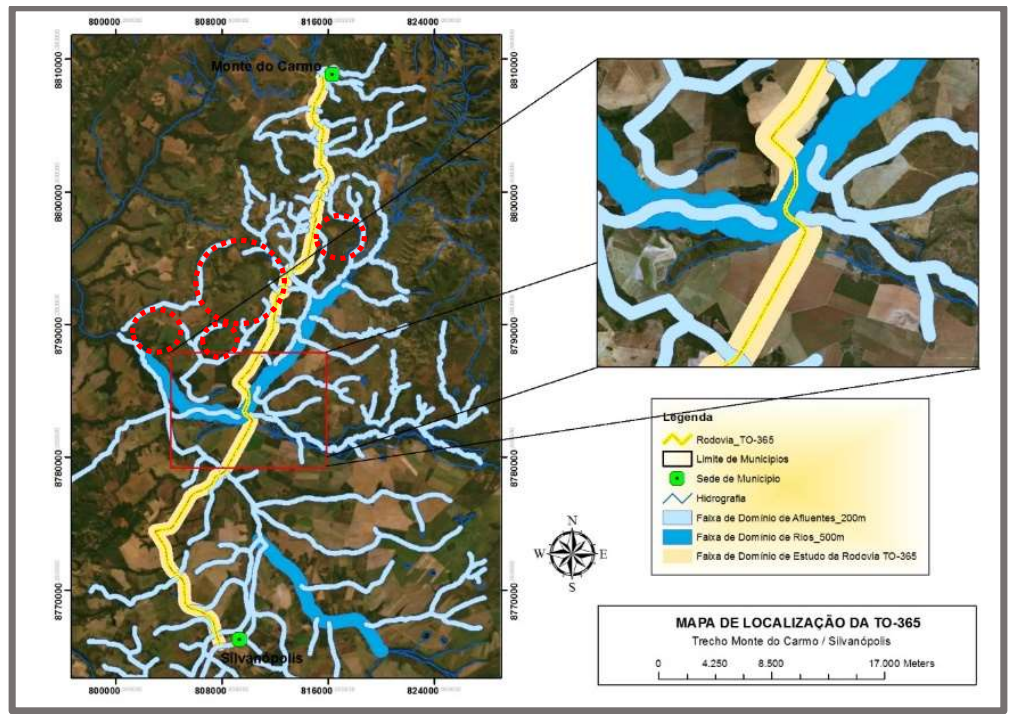

Figura 10: Rede de drenagem e rodovias com suas respectivas faixas de proteção. Fonte: Elaboração própria (2019).

A escolha da área para construção de aterros deve atender a legislação municipal de Uso e Ocupação do Solo, com preferência daquelas antropizadas e com mínimo potencial de incorporação à zona urbana da sede, distritos ou povoados e de baixa valorização imobiliária (CONAMA no 237, 1997). Em análise comparativa de todos os mapas e critérios descritos, foram levantados alguns pontos (círculos vermelhos) que apresentam viabilidade técnica para construção do aterro consorciado (Figura 10).

\section{CONCLUSÕES}

Os municípios de Silvanópolis e Monte do Carmo apresentam grande necessidade de implantação de um aterro sanitário para descarte de seus resíduos, uma vez que sua condição atual se encontra inadequada, em lixões à céu aberto. Devido ao fato dos municípios serem de pequeno porte a implantação de um consórcio seria de suma importância, já que reduziria custos para ambos. Em análise de dados georreferenciados é possível garantir a viabilidade técnica para construção de tal aterro consorciado na região que liga os dois municípios.

\section{REFERÊNCIAS}


ABRELPE. Associação Brasileira de Empresas de Limpeza Pública e Resíduos Especiais. Panorama dos resíduos sólidos no Brasil. São Paulo: ABRELPE, 2017.

BENDA, F.. Favorabilidade de áreas para implantação de aterros controlados no município de Campos dos Goytacazes/RJ utilizando sistemas de informação geográfica. Dissertação (Mestrado em Engenharia Civil) Universidade Estadual do Norte Fluminense Darcy Ribeiro, Rio de Janeiro, 2008.

BLOOM, D. E.. 7 Billion and Counting. Science, Nova lorque, v.333, p.562-569, 2011.

BORN, V.. Avaliação da aptidão de áreas para a instalação de aterro sanitário com o uso de ferramentas de apoio à decisão por múltiplos critérios. Monografia (Graduação em Engenharia Ambiental) - Universidade do Vale do Taquari, Porto Alegre, 2013.

BRASIL. Lei n. 12.305, de 2 de agosto de 2010. Institui a Política Nacional de Resíduos Sólidos; altera a Lei no 9.605, de 12 de fevereiro de 1998; e dá outras providências. Brasília: DOU, 2010.

BRASIL. Resolução CONAMA n. 237, de 19 de dezembro de 1997. Dispõe sobre licenciamento ambiental; competência da União, Estados e Municípios; listagem de atividades sujeitas ao licenciamento; Estudos Ambientais, Estudo de Impacto Ambiental e Relatório de Impacto Ambiental.

BRASIL. Resolução CONAMA n. 404, de 11 de novembro de 2008. Estabelece critérios e diretrizes para o licenciamento ambiental de aterro sanitário de pequeno porte de resíduos sólidos urbanos. Brasília: DOU, 2008.

ELK, A. G. H. P.. Redução de emissões na disposição final. Rio de Janeiro: IBAM, 2007.

FELICORI, T. C.. Identificação de áreas adequadas para a construção de aterros sanitários e usinas de triagem e compostagem na mesorregião da zona da mata - Minas Gerais. Dissertação (Pós-Graduação em Engenharia Civil) Universidade Federal de Viçosa, Belo Horizonte, 2015.

GREGÓRIO, B. S.; AZEVEDO, G. M.; SOUZA, J. L.; SANTOS, P. S.. Avaliação de áreas para instalação de aterro sanitário no município de Barreiras, Bahia. In: SIMPÓSIO BRASILEIRO DE SENSORIAMENTO REMOTO, 16. Anais. Foz do Iguaçu: INPE, 2013.

IBGE. Instituto Brasileiro de Geografia e Estatística. Censo 2010. São Paulo: IBGE, 2010.

MONTEIRO, J. H. P.; FIGUEIREDO, A. F. M.; MELO, M. A. F.;
BRITO, J. C. X.; ALMEIDA, T. P. F.; MANSUR, G. L.. Manual de Gerenciamento Integrado de resíduos sólidos. Rio de Janeiro: IBAM, 2001.

MOREIRA, M. A. A.; LORANDI, R.; MORAES, M. E. B.. Caracterização de áreas preferenciais para a instalação de aterros sanitários no município de Descalvado (SP), na escala 1:50.000. Revista Brasileira de Cartografia, São Paulo, v.60, n.2, p.177-194, 2008.

OLIVEIRA, T. B.; GALVÃO JUNIOR, A. C.. Planejamento municipal na gestão dos resíduos sólidos urbanos e na organização da coleta seletiva. Engenharia Sanitária e Ambiental, Rio de Janeiro, v.21, n.1, p.55-64, 2016.

RAFAEL, L. F. A.; WITOLD, Z.. Incorporação de aterros a áreas urbanas. Boletim técnico da escola Politécnica da USP, Departamento de engenharia de construção civil. BT/PCC/466, 2007.

REICHERT, G. A.. Apoio à tomada de decisão por meio da avaliação do ciclo de vida em sistemas de gerenciamento integrado de resíduos sólidos urbanos: $\mathrm{O}$ caso de Porto Alegre. Tese (Doutorado em Recursos Hídricos e Saneamento Ambiental) - Universidade Federal Rio Grande do Sul, Porto Alegre, 2013.

RIBEIRO, R. L. P.. Análise da viabilidade ambiental e econômica para implantação de aterro sanitário em Sarandi - RS. Monografia (Graduação em Engenharia Ambiental) - Universidade de Passo Fundo, Porto Alegre, 2011.

RIKILS, V. S. S.. Estudo de viabilidade de um consórcio público intermunicipal de resíduos sólidos urbanos na região do sul do estado de Roraima, $\mathbf{R R}$, Brasil. Dissertação (Mestrado em Ambiente e Desenvolvimento) - Universidade do Vale do Taquari, Porto Alegre, 2015.

SEPLAN. Secretaria Do Planejamento. Perfil socioeconômico dos municípios secretaria do planejamento e orçamento. Palmas: SEPLAN, 2015.

SUZUKI, J. A. N.; GOMES, J.. Consórcios intermunicipais para a destinação de RSU em aterros regionais: estudo prospectivo para os municípios no Estado do Paraná. Engenharia Sanitária e Ambiental, Rio de Janeiro, v.14, n.2, p.155-158, 2009.

TEIXEIRA, D. R.; PAZ, F. N. V.; PRADO, G. L.; MARÓN, J. R. L.; MALVÁSIO, A.. Caracterização da disposição dos resíduos sólidos gerados no município de Palmas - Tocantins: um estudo de caso em quadras selecionadas. Revista Espaço \& Geografia, Brasília, v.16, n.1, p.1-39, 2013.

A CBPC - Companhia Brasileira de Produção Científica (CNPJ: 11.221.422/0001-03) detém os direitos materiais desta publicação. Os direitos referem-se à publicação do trabalho em qualquer parte do mundo, incluindo os direitos às renovações, expansões e disseminacões da contribuicão, bem como outros direitos subsidiários. Todos os trabalhos publicados eletronicamente poderão posteriormente ser publicados em coletâneas impressas sob coordenação da Sustenere Publishing da Companhia Brasileira de Produção Científica e seus parceiros autorizados. Os (as) autores (as) preservam os direitos autorais, mas não têm permissão para a publicação da contribuição em outro meio, impresso ou digital, em português ou em tradução. 